\title{
Disruption of P2X4 purinoceptor and suppression of the inflammation associated with cerebral aneurysm formation
}

\author{
Miyuki Fukuda, MD, ${ }^{1,2}$ Shunichi Fukuda, MD, Joji Ando, MD, ${ }^{3}$ Kimiko Yamamoto, PhD, ${ }^{4}$ \\ Naohiro Yonemoto, MPH, ${ }^{5}$ Takashi Suzuki, PhD, ${ }^{1,6}$ Youko Niwa, PhD, ${ }^{1}$ Takayuki Inoue, PhD, \\ Noriko Satoh-Asahara, MD, ${ }^{7}$ Koji Hasegawa, MD, ${ }^{8}$ Akira Shimatsu, MD, ${ }^{9}$ and \\ Tetsuya Tsukahara, MD'
}

\begin{abstract}
'Department of Neurosurgery, National Hospital Organization Kyoto Medical Center, Kyoto; '2Department of Neurosurgery, Graduate School of Medicine, Kyoto University, Kyoto; ${ }^{3}$ Laboratory of Biomedical Engineering, School of Medicine, Dokkyo Medical University, Mibu City, Tochigi; ${ }^{2}$ Department of Biomedical Engineering, Graduate School of Medicine, University of Tokyo, Bunkyo-ku, Tokyo; Departments of ${ }^{5}$ Biostatistics and ${ }^{6}$ Psychiatry, Graduate School of Medicine, Kyoto University, Kyoto; and 'Department of Endocrinology, Metabolism, and Hypertension Research, Clinical Research Institute, ${ }^{8}$ Division of Translational Research, and ${ }^{~} \mathrm{Clinical}$ Research Institute, National Hospital Organization Kyoto Medical Center, Kyoto, Japan
\end{abstract}

OBJECTIVE There are no effective therapeutic drugs for cerebral aneurysms, partly because the pathogenesis remains unresolved. Chronic inflammation of the cerebral arterial wall plays an important role in aneurysm formation, but it is not clear what triggers the inflammation. The authors have observed that vascular endothelial P2X4 purinoceptor is involved in flow-sensitive mechanisms that regulate vascular remodeling. They have thus hypothesized that shear stress-associated hemodynamic stress on the endothelium causes the inflammatory process in the cerebral aneurysm development.

METHODS To test their hypothesis, the authors examined the role of P2X4 in cerebral aneurysm development by using $P 2 X 4^{--}$mice and rats that were treated with a P2X4 inhibitor, paroxetine, and subjected to aneurysm-inducing surgery. Cerebral aneurysms were induced by unilateral carotid artery ligation and renovascular hypertension.

RESULTS The frequency of aneurysm induction evaluated by light microscopy was significantly lower in the $P 2 \times 4^{-/-}$ mice $(p=0.0488)$ and in the paroxetine-treated male $(p=0.0253)$ and female $(p=0.0204)$ rats compared to control mice and rats, respectively. In addition, application of paroxetine from 2 weeks after surgery led to a significant reduction in aneurysm size in the rats euthanized 3 weeks after aneurysm-inducing surgery $(p=0.0145)$, indicating that paroxetine suppressed enlargement of formed aneurysms. The mRNA and protein expression levels of known inflam-

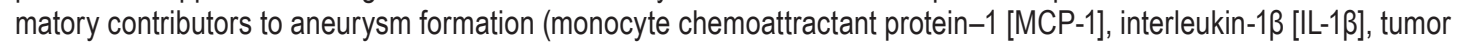
necrosis factor- $\alpha$ [TNF $\alpha$ ], inducible nitric oxide synthase [iNOS], and cyclooxygenase-2 [COX-2]) were all significantly elevated in the rats that underwent the aneurysm-inducing surgery compared to the nonsurgical group, and the values in the surgical group were all significantly decreased by paroxetine administration according to quantitative polymerase chain reaction techniques and Western blotting. Although immunolabeling densities for COX-2, iNOS, and MCP-1 were not readily observed in the nonsurgical mouse groups, such densities were clearly seen in the arterial wall of $P 2 X 4^{+/+}$ mice after aneurysm-inducing surgery. In contrast, in the P2X $4^{--}$mice after the surgery, immunolabeling of COX-2 and iNOS was not observed in the arterial wall, whereas that of MCP-1 was readily observed in the adventitia, but not the intima.

CONCLUSIONS These data suggest that P2X4 is required for the inflammation that contributes to both cerebral aneu-

ABBREVIATIONS ACA = anterior cerebral artery; $\mathrm{BA}=$ basilar artery; $\mathrm{COX}-2$ = cyclooxygenase-2; $\mathrm{GAPDH}=$ glyceraldehyde-3-phosphate dehydrogenase; $\mathrm{ICA}=$ internal carotid artery; IC $\mathrm{C}_{50}=$ median inhibitory concentration; IEL = internal elastic lamina; IL-1 $\beta=$ interleukin-1 $\beta ;$ iNOS = inducible nitric oxide synthase; $M C A=$ middle cerebral artery; MCP-1 = monocyte chemoattractant protein-1; OlfA = olfactory artery; $\mathrm{PPCR}=$ quantitative polymerase chain reaction; $\mathrm{SBP}=$ systolic blood pressure; TNF $\alpha=$ tumor necrosis factor $-\alpha$; WSS $=$ wall shear stress.

SUBMITTED January 31, 2019. ACCEPTED September 24, 2019.

INCLUDE WHEN CITING Published online December 20, 2019; DOI: 10.3171/2019.9.JNS19270. 
rysm formation and growth. Enhanced shear stress-associated hemodynamic stress on the vascular endothelium may trigger cerebral aneurysm development. Paroxetine may have potential for the clinical treatment of cerebral aneurysms, given that this agent exhibits efficacy as a clinical antidepressant.

https://thejns.org/doi/abs/10.3171/2019.9.JNS19270

KEYWORDS wall shear stress; vascular flow-sensitive mechanism; cerebral aneurysm formation; inflammation; therapeutic drug; animal model; vascular disorders

$\mathrm{T}$ HE rupture of a cerebral aneurysm is a major cause of life-threatening subarachnoid hemorrhages. Currently there are surgical interventions but no effective drug treatment for cerebral aneurysms. This is mainly because the mechanisms underlying aneurysm formation are not well understood. Several researchers report that chronic inflammation is involved in cerebral aneurysm

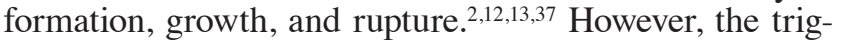
gers for the inflammatory reaction remain unclear.

Hemodynamic involvement in aneurysm development

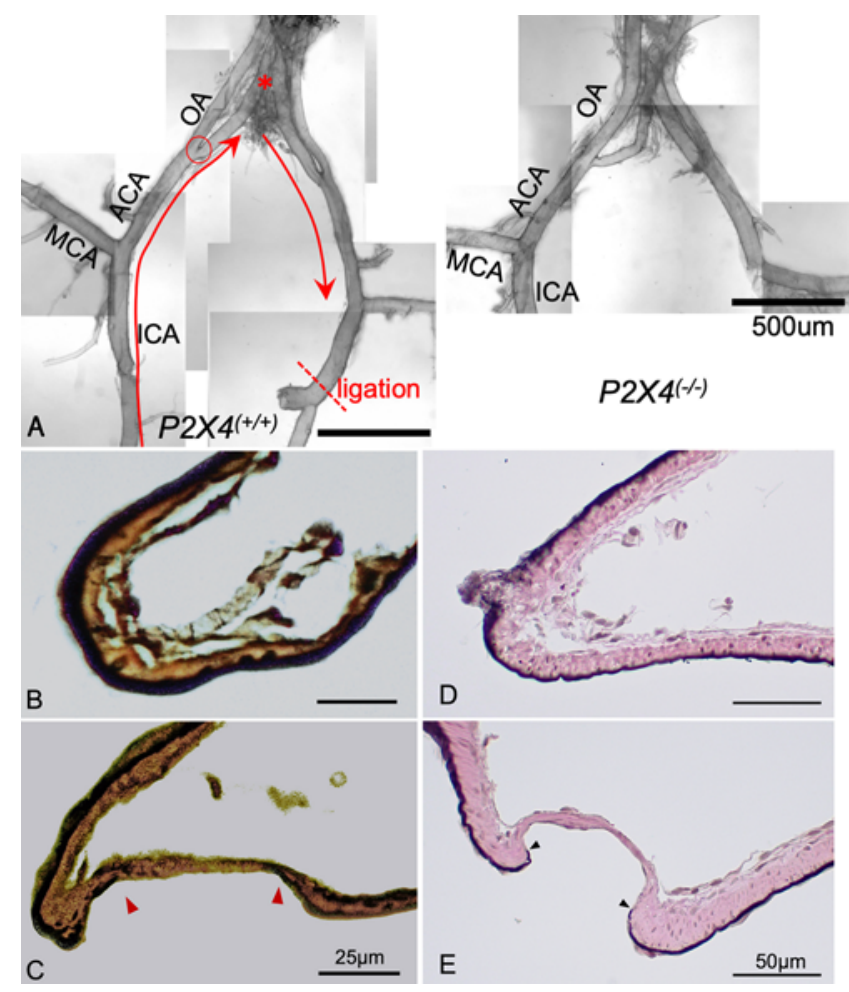

FIG. 1. A: Representative images from the anatomical examinations of the circle of Willis in wild-type C57BL/6 $\left(P 2 \times 4^{+/+}\right)$and P2X4 genetic knockout $\left(P 2 X 4^{--}\right)$mice without aneurysm-inducing surgery. There were no observable anatomical differences in the circle of Willis between the $P 2 X^{+/+}$and $P 2 X 4^{-l-}$ mice. The $P 2 X 4^{+/+}$panel shows a schema of the cerebral aneurysm-inducing surgery. Cerebral aneurysms are induced in the ACA (red asterisk) and at the bifurcation site of the ACA-OlfA (OA) (red circle) where the blood flow (red arrows) is increased consequent to the unilateral carotid artery ligation (red dashed line). B-E: Representative images of the apex of the right ACA-OlfA bifurcation without ( $B$ and $D$ ) and with ( $C$ and $E$ ) experimentally induced aneurysms in mice ( $B$ and C) and rats ( $D$ and E). Note that IEL disruption can be observed on the wall of the induced aneurysms (red and black arrowheads). Elastica van Gieson staining. has been empirically observed. ${ }^{24,26,40}$ Occlusion of a unilateral internal carotid artery (ICA) can lead to an aneurysm in the anterior communicating artery, where the blood flow is increased in a compensatory manner. ${ }^{40}$ Local increases in hemodynamic stress caused by disturbed hemodynamics in an asymmetrically shaped circle of Willis $^{26}$ - as well as a systemic rise in hemodynamicsmay be key requirements for aneurysm formation. The model of cerebral aneurysm used in the present study is experimentally induced in mice and rats through unilateral common carotid artery ligation and renovascular hypertension with a mechanism similar to that observed in humans (Fig. 1A). ${ }^{16,20-22,33}$ The resulting aneurysms have microstructural features similar to those seen in human cerebral aneurysms. ${ }^{20,22}$

During an early phase of aneurysm development at the arterial bifurcation in the animal model, vascular endothelial degeneration and disruption of the internal elastic lamina (IEL) occur almost exclusively at the distal side of the major branch adjacent to the apex; aneurysmal bulging is also observed in this area. ${ }^{22}$ Interestingly, hemorheological studies in rats have shown that wall shear stress (WSS) increases and is greatest in this same area during early aneurysm development. ${ }^{35}$ We thus hypothesized that cerebral aneurysms are induced when endothelial cells sense an increase in WSS and respond by triggering the induction of biochemical mediators that damage the vascular wall components, thereby giving rise to the cerebral aneurysm (WSS mechanotransduction hypothesis). In support of this hypothesis, we have demonstrated that inducible nitric oxide synthase (iNOS) is located in human and rat cerebral aneurysms, and not only iNOS inhibition but also WSS reduction reduces cerebral aneurysm formation in rats. ${ }^{15}$

Several inflammatory mediators, mainly monocyte chemoattractant protein-1 (MCP-1), cyclooxygenase-2 (COX-2), tumor necrosis factor- $\alpha$ (TNF $\alpha)$, and interleukin-1 $\beta$ (IL-1 $\beta$ ), have been reported to contribute to cerebral aneurysm development, and these inflammatory factors are currently thought to be the main chemical mediators involved in cerebral aneurysm formation. ${ }^{2,12,13,37}$ We therefore hypothesized that vascular endothelial cells may sense enhanced WSS-related hemodynamic stress over normal physiological levels, and may then trigger the expressions of inflammatory factors contributing to aneurysm formation.

We previously showed that $\mathrm{P} 2 \mathrm{X} 4$ purinoceptor is involved in the shear stress response of vascular endothelial cells, contributing to vascular remodeling. ${ }^{42} \mathrm{P} 2 \mathrm{X} 4$ receptors are widely distributed in several organs, and are the most abundantly expressed $\mathrm{P} 2 \mathrm{X}$ receptor subtype in vascular endothelial cells. P2X4 is one of the most sensitive 
TABLE 1. The numbers of animals used in the present experiments

\begin{tabular}{|c|c|c|c|c|c|}
\hline Experiment & Animals & Group & No. & Timing of Euthanasia & Withdrawals \\
\hline \multirow{4}{*}{$\begin{array}{l}\text { Effect of P2X4 disruption on aneu- } \\
\text { rysm formation* }\end{array}$} & \multirow[t]{2}{*}{$P 2 X 4^{+/+}$} & Control & 10 & NA & NA \\
\hline & & Surgery & 40 & 5 mos after surgery & 19 died during 5-mo aneurysm induction period \\
\hline & \multirow[t]{2}{*}{$P 2 \times 4^{-/-}$} & Control & 10 & NA & NA \\
\hline & & Surgery & 40 & 5 mos after surgery & 21 died during 5-mo aneurysm induction period \\
\hline \multirow{2}{*}{$\begin{array}{l}\text { Anatomical examination of the } \\
\text { circle of Willis }\end{array}$} & $P 2 X 4^{+/+}$ & Control & 12 & NA & NA \\
\hline & $P 2 \times 4^{-/-}$ & Control & 12 & NA & NA \\
\hline \multirow{6}{*}{$\begin{array}{l}\text { Effect of P2X4 inhibition on aneu- } \\
\text { rysm formation }\end{array}$} & \multirow[t]{3}{*}{ Male rats } & Control & 10 & NA & NA \\
\hline & & Surgery $3 w$ & 15 & 3 wks after surgery & 1 died immediately after surgery \\
\hline & & Surgery+PRX & 15 & 3 wks after surgery & NA \\
\hline & \multirow[t]{3}{*}{ Female rats } & Control & 10 & NA & NA \\
\hline & & Surgery $3 w$ & 15 & 3 wks after surgery & 1 died immediately after surgery \\
\hline & & Surgery+PRX & 15 & 3 wks after surgery & $\begin{array}{l}\text { An osmotic pump in a rat deviated during the } \\
\text { aneurysm induction period }\end{array}$ \\
\hline \multirow{3}{*}{$\begin{array}{l}\text { Effect of P2X4 inhibition on aneu- } \\
\text { rysm growth }\end{array}$} & \multirow[t]{3}{*}{ Female rats } & Surgery $2 w$ & 15 & 2 wks after surgery & 1 died immediately after surgery \\
\hline & & Surgery $3 w$ & 15 & 3 wks after surgery & NA \\
\hline & & Surgery+PRX for $1 \mathrm{w}$ & 15 & 3 wks after surgery & NA \\
\hline \multirow[t]{3}{*}{ PCR experiments } & \multirow[t]{3}{*}{ Male rats } & Control & 10 & NA & NA \\
\hline & & Surgery $3 w$ & 8 & 3 wks after surgery & NA \\
\hline & & Surgery+PRX & 8 & 3 wks after surgery & NA \\
\hline \multirow[t]{3}{*}{ Western blotting experiments } & \multirow[t]{3}{*}{ Female rats } & Control & 5 & NA & NA \\
\hline & & Surgery $3 w$ & 6 & 3 wks after surgery & NA \\
\hline & & Surgery+PRX & 6 & 3 wks after surgery & NA \\
\hline
\end{tabular}

$\mathrm{NA}=$ not applicable; $\mathrm{PRX}=$ paroxetine; $P 2 X 4^{+/+}=$male wild-type $\mathrm{C} 57 \mathrm{BL} / 6$ mice; $P 2 X 4^{-/-}=$male $\mathrm{P} 2 \mathrm{X} 4$ genetic knockout mice; surgery $2 \mathrm{w}=$ rats euthanized 2 weeks after aneurysm-inducing surgery; surgery $3 w=$ rats euthanized 3 weeks after aneurysm-inducing surgery; surgery+PRX = rats euthanized 3 weeks after aneurysminducing surgery with paroxetine treatment for 3 weeks; surgery+PRX for $1 \mathrm{w}=$ rats euthanized 3 weeks after aneurysm-inducing surgery with paroxetine treatment for the final week.

* In mouse immunostaining experiments, 10 animals of each group of the experiments for the effect of P2X4 disruption on aneurysm formation were used.

purinergic receptors, and the major contributor to adenosine 5'-triphosphate- and flow-induced $\mathrm{Ca}^{2+}$ influx in endothelial cells..$^{39,42}$

We therefore examined the role of P2X4 in the formation and growth of the cerebral aneurysm by assessing the effects of $\mathrm{P} 2 \mathrm{X} 4$ genetic knockout $\left(P 2 \mathrm{X}^{-{ }^{-}}\right)$in mice and rats administered paroxetine, a $\mathrm{P} 2 \mathrm{X} 4$ inhibitor, ${ }^{34}$ on the incidence and extent of cerebral aneurysm development. We evaluated the expression of several well-known aneurysm formation-implicated inflammatory molecules by performing immunohistochemical experiments and using quantitative polymerase chain reaction (qPCR) and Western blotting methods.

\section{Methods}

\section{Animals}

All animal experiments were conducted in compliance with the US National Institutes of Health Guide for the Care and Use of Laboratory Animals and approved by the Kyoto Medical Center Animal Use Committee. Sixty-two

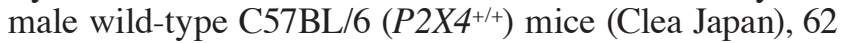
male $P 2 X 4^{-/-}$mice, ${ }^{42}$ and 66 male and 102 female SpragueDawley rats (Clea Japan) were used. The confirmation of $\mathrm{P} 2 \mathrm{X} 4$ deficiency is described elsewhere. ${ }^{42}$ Table 1 sum- marizes the numbers of control and experimental animals used in each experiment.

\section{Cerebral Aneurysm-Inducing Surgery in Mice and Rats}

The rat and mouse model of cerebral aneurysm used herein is an established model that has been used in many studies since it was proposed in 1978..$^{2-4,13-16,20-22,33,35}$ The details of the surgical method of aneurysm induction are provided elsewhere. ${ }^{2,14,15,20,33}$ We used a modified version of the model reported in 2017. ${ }^{2}$ Briefly, 7-week-old animals were subjected to ligation of the left carotid artery and the left renal artery under general anesthesia after inhalation of isoflurane $(5 \mathrm{~L} / \mathrm{min})$ in the mice or intraperitoneal injection of sodium pentobarbital $(40 \mathrm{mg} / \mathrm{kg})$ in the rats (Fig. 1A).

In the experiments examining the effect of the P2X4 inhibitor paroxetine ${ }^{34}$ on cerebral aneurysm induction, paroxetine $(8 \mathrm{mg} / \mathrm{kg} /$ day in dimethyl sulfoxide [DMSO]) and DMSO alone were administered just after surgery to the paroxetine-treated rats and control surgical rats, respectively, via an osmotic pump (model \#2ML4; Alzet Osmotic Pumps) for 3 weeks. In the experiments investigating effects of paroxetine on aneurysm growth, osmotic pumps (model \#2ML1) with and without paroxetine were subcutaneously placed in the rats 2 weeks after surgery. 
Selection of the rats receiving or not receiving paroxetine treatment was performed at random. After aneurysminducing surgery, the animals were fed a special chow containing $8 \%$ sodium chloride and $0.12 \% 3$-aminopropionitrile (\#A0408; Tokyo Chemical Industry), which is an inhibitor of lysyl oxidase catalyzing the cross-linking of collagen and elastin. Blood pressure was measured by the tail-cuff method (MK-2000 monitor; Muromachi). For the euthanasia procedure, animals in the surgical groups were transcardially perfused with $4 \%$ paraformaldehyde under general anesthesia 3 weeks (rats) or 5 months (mice) after the surgery unless otherwise noted (Table 1).

\section{Histological Examinations}

The arachnoid membrane containing the circle of Willis was stripped from each animal's brain, and the right anterior cerebral artery (ACA)-olfactory artery (OlfA) bifurcation was cut down and prepared as 5- $\mu \mathrm{m}$-thick frozen sections. The sections were subjected to Elastica van Gieson staining to visualize the elastic lamina, collagen fibers, and muscle fibers in the arterial wall.

\section{Anatomical Examinations of the Circle of Willis in the $P 2 X^{+/+}$and $P 2 X 4^{-/-}$Mice}

$P 2 X 4^{+/+}$and $P 2 X 4^{-/-}$mice that did not undergo surgery were transcardially perfused with $4 \%$ paraformaldehyde under general anesthesia. The arachnoid membrane containing the circle of Willis was stripped from each animal, and the arterial specimens were stained with Pyoktanin blue (Wako Pure Chemical Industries). The diameters immediately after the origin of MCA, ACA, and OlfA and immediately before the top of the ICA and basilar artery (BA) were measured using ImageJ software (NIH). The measurement was performed by 2 persons in a blind manner and the average value of the measurements was adopted.

\section{Evaluation of Induced Cerebral Aneurysms and Early-Phase Cerebral Aneurysm Changes}

To evaluate the incidence and maximum internal diameter of the induced aneurysms, we defined cerebral aneurysm as an IEL disruption with an outward bulging of the arterial wall detected by light microscopy, in accord with the observations of aneurysm development (Fig. 1B-E). ${ }^{2,14,15,20,33}$ To evaluate the progression of early-phase aneurysm development in the mice, we scored the magnitude of IEL disruption as follows: grade 0, no IEL disruption; grade 1, IEL disruption < $10 \mu \mathrm{m}$ long; grade 2, IEL disruption $\geq 10 \mu \mathrm{m}$ long. The measurement of IEL disruption was performed using ImageJ software by 2 persons in a blind manner and the average value of the measurements was adopted.

\section{RNA Isolation and Quantitative Reverse Transcription PCR in the Rats}

Total RNA of parts of the circle of Willis (from the right middle cerebral artery [MCA] to the left OlfA) of male rats was prepared using an RNeasy Fibrous Tissue Mini Kit (Qiagen). The total RNA was transcribed to cDNA by using a High Capacity cDNA Reverse Tran- scription Kit (Life Technologies). PCR assessments were performed using a 7300 RealTime PCR System (Applied Biosystems) with Power SYBR Green PCR Master Mix (Applied Biosystems). $32 \mathrm{MG}$ was used as an internal control for the qPCR.

\section{Primer Sets Used for the qPCR \\ B2MG \\ 5'-TCTGGACCCTTGTTTGAGGAACC-3', forward; 5'-TTGTGCCAGAGTGAAGTGAAGTGG-3', reverse.}

COX-2

5'-TCAGTATGAGCCTGCTGGTTTGG-3', forward; 5'-CCGGGTCTGATGATGTATGCTACC-3', reverse.

TNF $\alpha$

5'-CTCCTGGTATGAAGTGGCAAATCG-3', forward; 5'-TGGCATGGATCTCAAAGACAACC-3', reverse.

MCP-1

5'-TGCTGAAGTCCTTAGGGTTGATGC-3', forward; 5'-GCAGCAGGTGTCCCAAAGAAGC-3', reverse.

IL-1 $\beta$

5'-TGAAGCTGGATGCTCTCATCTGG-3', forward; 5'-TGAAGCAGCTATGGCAACTGTCC-3', reverse.

\section{iNOS}

5'-CAAAGAGGACTGTGGCTCTGACG-3', forward; 5'-CTGGCAGGATGAGAAGCTGAGG-3', reverse.

\section{Western Blotting in the Rats}

Parts of the circle of Willis of female rats were dissected, and then stored in $2 \%$ protease and $2 \%$ phosphatase inhibitor cocktail (NACALAI TESQUE). Tissues were then homogenized with a bead crusher (TAITEC) in radioimmunoprecipitation assay (RIPA) buffer. Protein samples were separated by $4 \%-20 \%$ gradient sodium dodecyl sulfate-polyacrylamide gel electrophoresis (SDS-PAGE) at $130 \mathrm{~V}$ for 50 minutes, and electrophoretically transferred to polyvinylidene difluoride (PVDF) membranes. The membranes were subsequently blocked in Blocking One (\#03953-95; NACALAI TESQUE) overnight and treated with primary antibodies for 1 hour. They were then incubated with secondary antibody for 30 minutes, reacted with an ECL Prime Western Blotting Detection Kit (\#RPN2232; GE Healthcare), and detected with the Chemi Doc Imaging System (Bio-Rad). The protein expression was normalized to glyceraldehyde-3-phosphate dehydrogenase (GAPDH) expression (anti-rabbit GAPDH, 1:1000, \#10494-1-AP; Proteintech Group).

\section{Primary Antibodies for Western Blotting}

Western blotting was performed with the following primary antibodies: rabbit anti-IL-1 $\beta$ antibody (1:200, \#BS-6319R; Bioss Antibodies); rabbit anti-iNOS antibody (1:1000, \#GTX130246; GeneTex); rabbit anti-TNFa antibody (1:1000, \#17590-1-AP; Proteintech Group); mouse 


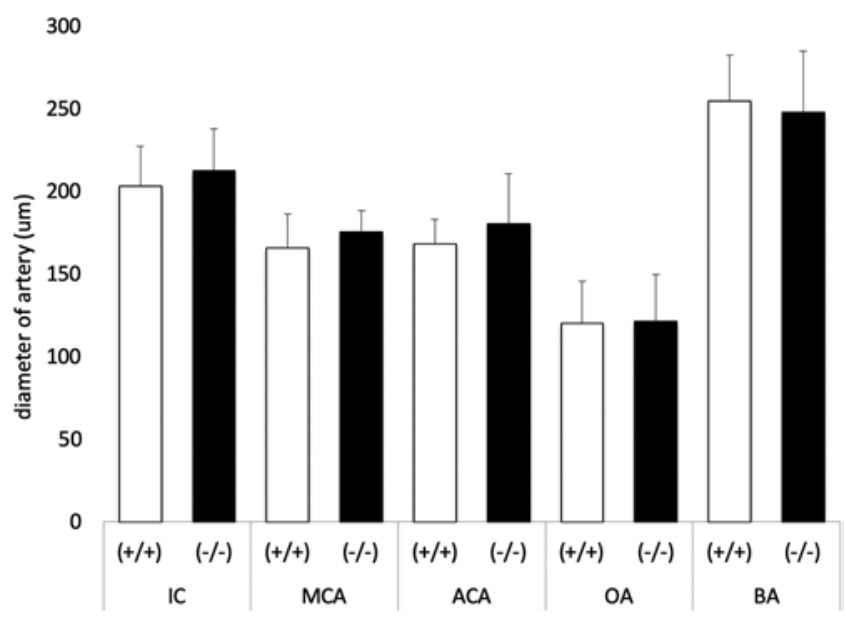

FIG. 2. Bar graph showing arterial diameters of the circle of Willis in wild-type C57BL/6 $\left(P 2 X 4^{+/+}\right)$and P2X4 genetic knockout $\left(P 2 X 4^{--}\right)$mice without aneurysm-inducing surgery (mean $\pm S D$ ). There were no significant differences in the diameters of each cerebral artery between the $P 2 X^{+/+}$and $P 2 X 4^{---}$mice according to the Student t-test. There were 12 animals in each group. IC $=I C A ; O A=$ OlfA; um = micrometers; $(+/+)=$ $P 2 X 4^{+/+}$mice; $(-/-)=P 2 X 4^{-l-}$ mice.

anti-MCP-1 antibody (1:1000, \#66272-1-Ig; Proteintech Group); and rabbit anti-COX-2 antibody (1:1000, \#4842; Cell Signaling Technology).

\section{Immunohistochemistry}

The immunohistochemical studies were performed as described previously. ${ }^{2,14}$ Briefly, histological sections were blocked with $5 \%$ donkey or goat serum (Jackson ImmunoResearch) and incubated with primary antibodies diluted at $4{ }^{\circ} \mathrm{C}$ overnight. Subsequently, the fluorescence-conjugated secondary antibodies (Jackson ImmunoResearch) were applied for 1 hour. The immunolabeled sections were analyzed under a confocal fluorescence microscope (Lsm710; Carl Zeiss Microscopy). All imaging parameters (laser power, imaging duration, photomultiplier tube gain, scanning speed, and averaging values) were the same for each primary antibody.

\section{Primary Antibodies for Immunohistochemistry}

Immunohistochemistry was performed with the following primary antibodies: goat polyclonal anti-MCP-1 antibody (1:100, \#sc-1785; Santa Cruz Biotechnology); rat polyclonal anti-CD31 antibody (1:100, \#550274; BD Biosciences); rabbit polyclonal anti-iNOS antibody (1:100, \#ab15323; Abcam); mouse monoclonal anti-cathepsin L antibody (1:200, \#ab6314; Abcam); and mouse polyclonal anti-COX-2 antibody (1:100, \#160126; Cayman Chemical).

\section{Statistical Analysis}

The continuous data are presented as the mean \pm SD. The continuous variables between 2 groups were examined with the Student t-test and the continuous variables among more than 2 groups were examined with an ANOVA followed by the Tukey-Kramer honestly significant difference test. The difference in the incidence of induced aneurysm between groups was analyzed using Fisher's exact test. The grade scales of IEL disruption were examined using the Cochran-Armitage trend test. Differences were considered significant at $\mathrm{p}<0.05$. All analyses were performed with the statistical software package JMP, version 11.0.0 (SAS Institute).

\section{Results}

\section{Anatomical Examinations of the Circle of Willis in the $P 24^{+/+}$and $P 2 X 4^{-/-}$Mice Without Aneurysm-Inducing Surgery}

There were no observable anatomical differences in the circle of Willis between the $P 2 X 4^{+/+}$and $P 2 X 4^{-/-}$mice without aneurysm-inducing surgery (Fig. 1A), and no cerebral aneurysm was detected in either of the nonsurgical mouse groups. There were also no significant differences in the arterial diameters of the circle of Willis between the $P 2 X 4^{+/+}$and $P 2 X 4^{-/}$mice (Fig. 2).

\section{The Effect of P2X4 Disruption on Cerebral Aneurysm Formation in Mice After Aneurysm-Inducing Surgery}

The cerebral aneurysm-generating surgery induced a cerebral aneurysm in $57 \%$ of the $P 2 \times 4^{+/+}$mice (12 of 21 ) but in only $26 \%$ of the $P 2 X 4^{-/-}$mice ( 5 of $19, \mathrm{p}=0.0488$; Table 2$)$. In addition, after the aneurysm-inducing surgery, the average score for disruption of the IEL, an indicator of early-phase aneurysm development, ${ }^{22,33}$ was significantly smaller in the $P 2 X 4^{-/-}$mice compared to the $P 2 X 4^{+/+}$mice $(\mathrm{p}=0.0122)$. IEL disruption $\geq 10 \mu \mathrm{m}$ in length, indicating severe damage to the IEL, was observed in 12 of the 21 $P 2 X 4^{+/+}$mice, but in only 5 of the $19 P 2 X 4^{-/-}$mice. The average systolic blood pressure (SBP) of the $P 2 X 4^{+/+}$mice

TABLE 2. The effect of P2X4 disruption on cerebral aneurysm formation in mice

\begin{tabular}{|c|c|c|c|c|c|c|c|c|}
\hline \multirow[b]{2}{*}{ Mouse Group } & \multirow[b]{2}{*}{ No. } & \multirow[b]{2}{*}{ Induced Aneurysms } & \multirow[b]{2}{*}{ Induction Rate } & \multirow[b]{2}{*}{ p Value } & \multicolumn{3}{|c|}{ IEL Grade } & \multirow[b]{2}{*}{ p Value } \\
\hline & & & & & 0 & 1 & 2 & \\
\hline$P 2 \times 4^{+/+}$ & 21 & 12 & $57 \%$ & - & 3 & 6 & 12 & - \\
\hline$P 2 \times 4^{-/-}$ & 19 & 5 & $26 \%$ & $0.0488^{*}$ & 8 & 6 & 5 & $0.0122 \dagger$ \\
\hline $\begin{array}{l}\text { _- = no comparis } \\
\text { Incidence of cere } \\
\text { disruption scores } \\
{ }^{*} \text { Fisher's exact te } \\
\text { † Cochran-Armita }\end{array}$ & $\begin{array}{l}\text { arge } \\
\text { ane } \\
\text { poir }\end{array}$ & $\begin{array}{l}\text { sm induction and IEL d } \\
\text { alues. }\end{array}$ & tion scores betv & $n P 2 X 4^{+-}$ & $\times 4$ & & $d_{u}$ & yery. IEL \\
\hline
\end{tabular}


TABLE 3. The effect of the P2X4 inhibitor paroxetine on cerebral aneurysm formation and growth in rats after aneurysm-inducing surgery

\begin{tabular}{|c|c|c|c|c|c|c|}
\hline Rat Group & No. & Induced Aneurysms & Induction Rate & p Value & Maximum Internal Diameter $(\mu \mathrm{m})$ & $p$ Value \\
\hline \multicolumn{7}{|l|}{ Male rats } \\
\hline Surgery $3 w$ & 14 & 14 & $100 \%$ & - & $80.9 \pm 36.2$ & - \\
\hline Surgery+PRX & 15 & 10 & $67 \%$ & $0.0253^{*}$ & $43.5 \pm 35.8$ & $0.0093 \dagger$ \\
\hline \multicolumn{7}{|l|}{ Female rats } \\
\hline Surgery $3 w$ & 14 & 14 & $100 \%$ & - & $79.6 \pm 18.8$ & - \\
\hline Surgery+PRX & 14 & 9 & $64 \%$ & $0.0204^{*}$ & $45.3 \pm 32.3$ & $0.0006 \dagger$ \\
\hline \multicolumn{7}{|l|}{ Female rats } \\
\hline Surgery $2 w$ & 14 & 14 & $100 \%$ & - & $74.4 \pm 18.8$ & - \\
\hline Surgery $3 w$ & 15 & 15 & $100 \%$ & - & $81.8 \pm 21.7$ & - \\
\hline Surgery+PRX for $1 w$ & 15 & 15 & $100 \%$ & - & $60.3 \pm 19.3$ & $0.0145 \ddagger$ \\
\hline
\end{tabular}

- = no comparison target.

Incidence and size of induced cerebral aneurysms in male and female rats after aneurysm-inducing surgery with and without paroxetine treatment for the entire periods or the last week. Maximum internal diameter values are shown as the mean \pm SD. surgery $2 \mathrm{w}=\mathrm{rats}$ euthanized 2 weeks after aneurysm-inducing surgery; surgery $3 w$ = rats euthanized 3 weeks after aneurysm-inducing surgery; surgery+PRX = rats euthanized 3 weeks after aneurysm-inducing surgery with paroxetine treatment for 3 weeks; surgery+PRX for $1 \mathrm{w}=$ rats euthanized 3 weeks after aneurysm-inducing surgery with paroxetine treatment for the final week.

* Fisher's exact test.

† Student t-test.

$\ddagger$ ANOVA followed by the Tukey-Kramer honestly significant difference test (surgery $3 w$ vs surgery+PRX for $1 w$ ).

was significantly increased by $12.8 \mathrm{~mm} \mathrm{Hg}$ at 5 months after the cerebral aneurysm-inducing surgery compared to the SBP before the surgery $(\mathrm{p}=0.0187)$. The average SBP of the $P 2 \mathrm{X}^{-/-}$mice was also significantly increased by $13.4 \mathrm{~mm} \mathrm{Hg}$ after the surgery $(\mathrm{p}=0.0158)$.

\section{The Effect of the P2X4 Inhibitor Paroxetine on Cerebral Aneurysm Induction in Rats After Aneurysm-Inducing Surgery}

The cerebral aneurysm-generating surgery induced a cerebral aneurysm in $100 \%$ of the male and female rats without paroxetine (14 of 14 in each animal group), but in only $67 \%$ and $64 \%$ of the male and female rats treated with paroxetine (10 of 15 males and 9 of 14 females, $\mathrm{p}=$ 0.0253 and 0.0204 , respectively; Table 3). The application of paroxetine led to a significant reduction of the size of the aneurysms in the male and female rats $(\mathrm{p}=0.0093$ and 0.0006 , respectively; Table 3 ). Without surgery, no cerebral aneurysm was observed in male and female rats. The average SBP of the male rats without and with paroxetine treatment was significantly increased by $79.1 \mathrm{~mm} \mathrm{Hg}$ in male rats without and $78.3 \mathrm{~mm} \mathrm{Hg}$ in male rats with paroxetine at 3 weeks after aneurysm-inducing surgery compared to before the surgery (both $\mathrm{p}<0.0001$ ). The average SBP of the female rats without and with paroxetine treatment was also significantly heightened by $69.7 \mathrm{~mm} \mathrm{Hg}$ in female rats without and $69.9 \mathrm{~mm} \mathrm{Hg}$ in female rats with paroxetine at 3 weeks after aneurysm-inducing surgery (both $\mathrm{p}<0.0001$ ).

\section{The Effect of the P2X4 Inhibitor Paroxetine on Cerebral Aneurysm Growth in Rats After Aneurysm-Inducing Surgery}

We also examined the effect of the P2X4 inhibition on aneurysm growth by administering paroxetine in the middle of the experiments to rats after aneurysm-inducing surgery. The size of aneurysms in the rats euthanized 3 weeks after aneurysm-inducing surgery with paroxetine treatment for the final week ("Surgery+PRX for 1w" group) was significantly smaller than that in rats euthanized 3 weeks after the surgery without paroxetine treatment ( $p=0.0145$; Table 3 ). The size of the aneurysms in the "Surgery+PRX for 1w" group exhibited a nonsignificant tendency to be smaller than that in the rats euthanized 2 weeks after aneurysm-inducing surgery $(60.3 \pm 19.3 \mu \mathrm{m}$ vs $74.4 \pm 18.8 \mu \mathrm{m}, \mathrm{p}=0.1512$ ). The cerebral aneurysmgenerating surgery induced an aneurysm in $100 \%$ of rats in all groups. The average SBP of the rats euthanized 2 weeks and 3 weeks after the surgery without paroxetine treatment was significantly increased by $71.8 \mathrm{~mm} \mathrm{Hg}$ at 2 weeks after aneurysm-inducing surgery and $70.4 \mathrm{~mm} \mathrm{Hg}$ at 3 weeks after surgery compared to before the surgery (both $\mathrm{p}<0.0001$ ). The average SBP of the rats with paroxetine treatment for the final week was also significantly heightened by $70.1 \mathrm{~mm} \mathrm{Hg}$ after aneurysm-inducing surgery $(\mathrm{p}<0.0001)$.

\section{The Effect of Paroxetine on the mRNA Expression Levels of Inflammatory Contributors to Aneurysm Formation in Rats After Aneurysm-Inducing Surgery}

The mRNA values of known inflammatory contributors to aneurysm formation, i.e., COX-2, TNF $\alpha$, MCP-1, iNOS, and IL-1 $\beta$, were significantly elevated in the male rats that underwent the aneurysm-inducing surgery compared to the nonsurgical group ( $<<0.0001, \mathrm{p}<0.0001, \mathrm{p}$ $<0.0001, p=0.0013$, and $\mathrm{p}=0.0004$, respectively; Fig. $3 \mathrm{~A}-\mathrm{E})$, and the values in the surgical group were significantly decreased by paroxetine $(\mathrm{p}<0.0001, \mathrm{p}=0.0003, \mathrm{p}$ $=0.0012, \mathrm{p}=0.0043$, and $\mathrm{p}=0.0031$, respectively). 


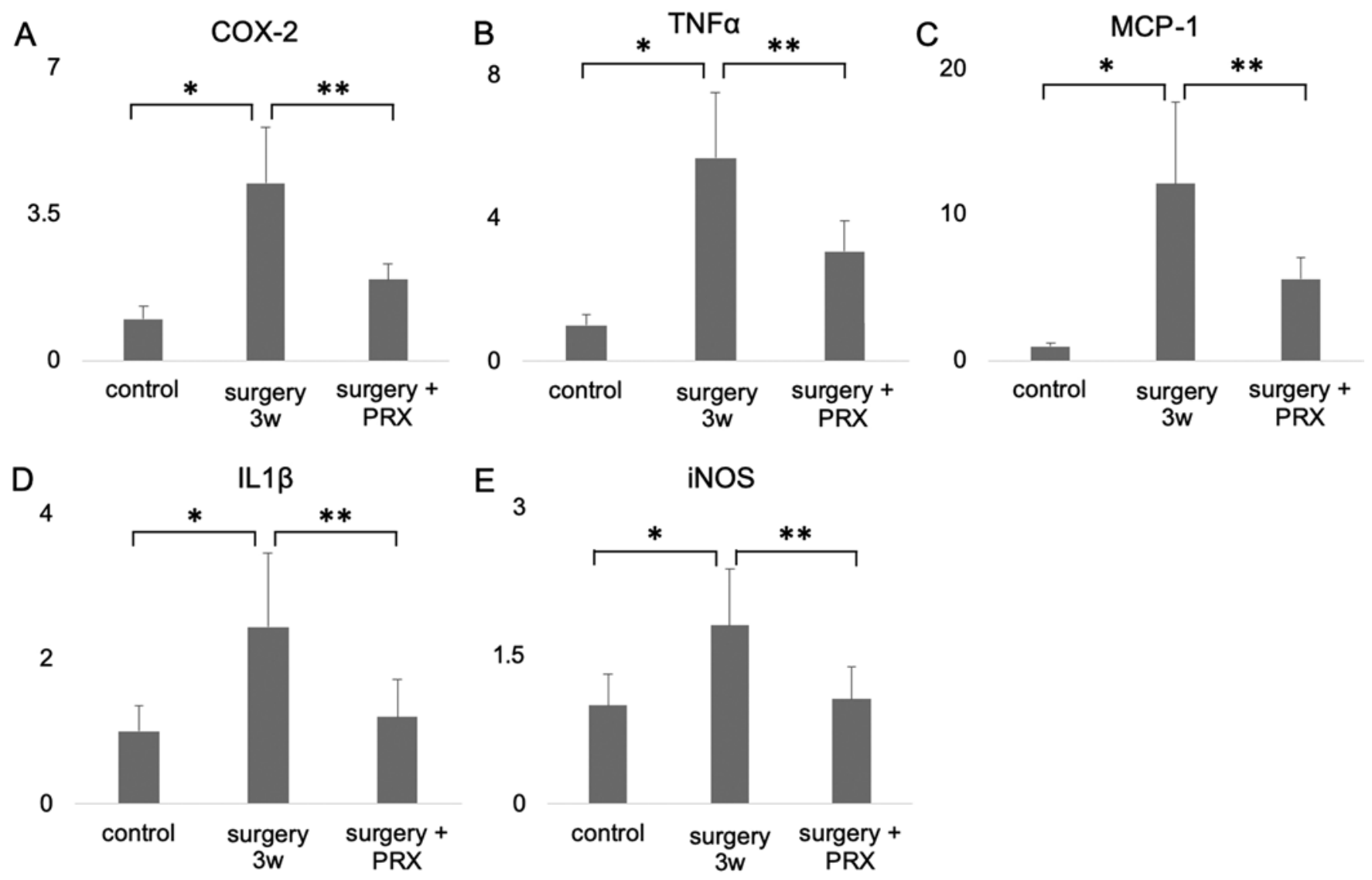

FIG. 3. Bar graphs showing the mRNA expressions of COX-2 (A), TNF $\alpha$ (B), MCP-1 (C), IL-1 (D), and iNOS (E) in experimentally induced cerebral aneurysms in male rats, by quantitative reverse transcription PCR analysis. The average mRNA expression levels of the control animals were set to 1.0, and the relative values (mean \pm SD) are shown. Correlations were examined by an ANOVA followed by the Tukey-Kramer honestly significant difference test. Control: rats without surgery $(n=10)$; surgery $3 w$ : rats euthanized 3 weeks after aneurysm-inducing surgery $(n=8)$; surgery+PRX: rats euthanized 3 weeks after aneurysm-inducing surgery and paroxetine treatment for 3 weeks $(n=8)$. ${ }^{*}$ Control versus surgery $3 w, p<0.0001(A), p<0.0001(B), p<0.0001(C)$, $p=0.0013(D)$, and $p=0.0004(E) .{ }^{*}$ Surgery 3 w versus surgery+PRX, $p<0.0001(A), p=0.0003(B), p=0.0012(C), p=0.0043$ (D), and $p=0.0031(E)$.

\section{The Effect of Paroxetine on the Protein Expression Levels of Inflammatory Contributors to Aneurysm Formation in Rats After Aneurysm-Inducing Surgery}

The protein values of COX-2, TNF $\alpha, \mathrm{MCP}-1$, iNOS, and IL-1 $\beta$ were significantly elevated in the female rats that underwent aneurysm-inducing surgery compared to the nonsurgical group $(\mathrm{p}=0.0035, \mathrm{p}<0.0001, \mathrm{p}<0.0001$, $p=0.0005$, and $p=0.0010$, respectively; Figs. 4 and 5), and the values in the surgical group were significantly decreased by paroxetine $(\mathrm{p}=0.0088, \mathrm{p}<0.0001, \mathrm{p}<0.0001$, $\mathrm{p}=0.0043$, and $\mathrm{p}=0.0277$, respectively).

\section{Immunohistochemical Distributions of Induced Mediators in Mice After Cerebral Aneurysm-Inducing Surgery}

In the absence of aneurysm-inducing surgery, immunolabeling densities for COX-2, iNOS, and MCP-1 were not readily observed in either $\mathrm{P} 2 \mathrm{X}^{4^{+/}}$or $\mathrm{P} 2 \mathrm{X}^{-/-}$mice (Figs. 6-8), whereas after the surgery such densities were clearly seen in the arterial wall of the $P 2 X 4^{+/+}$mice. In the $P 24^{4^{-/}}$mice after the surgery, immunolabeling of COX-2 and iNOS was not observed in the arterial wall, whereas that of MCP-1 was readily observed in the adventitia, but not the intima.

\section{Discussion}

Both the disruption and inhibition of $\mathrm{P} 2 \mathrm{X} 4$ purinoceptor resulted in a significant reduction of cerebral aneurysm induction, along with significant decreases in the degree of IEL disruption and the size of the aneurysms after aneurysm-inducing surgery (Tables 2 and 3). There was no appreciable difference in results between male and female rats. According to the qPCR and Western blotting analyses, the expression of the mRNA and protein levels for well-known inflammatory mediators contributing to cerebral aneurysm development, specifically COX-2, MCP-1, TNF $\alpha$, iNOS, and IL-1 $\beta$, was significantly increased in the animals that underwent the surgery compared to the nonsurgical group; all of these expression levels were significantly suppressed in the rats treated with the P2X4 inhibitor paroxetine after aneurysm-inducing surgery (Figs. $3-5$ ). Taken together, these results suggest that P2X4 is involved in the inflammation contributing to cerebral aneu- 


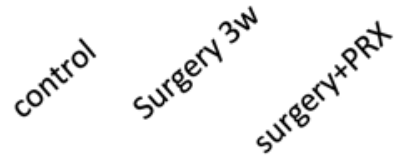

iNOS

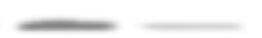

$\longleftarrow 131 \mathrm{kDa}$

IL1 $\beta$

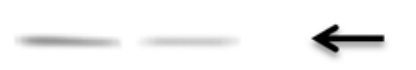

$30 \mathrm{kDa}$

coX-2

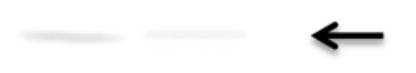

$74 \mathrm{kDa}$

MCP-1

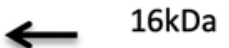

TNF $\alpha$
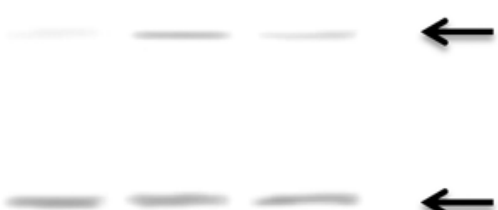

$26 \mathrm{kDa}$

\section{GAPDH}

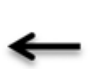

$36 \mathrm{kDa}$

FIG. 4. A representative image of Western blotting of parts of the circle of Willis (from the right MCA to the left OlfA) before and after cerebral aneurysm-inducing surgery in female rats.
\end{abstract}

rysm formation. Vascular endothelial cells may sense enhanced WSS-associated hemodynamics, and the sensing may cause the progression of a series of inflammatory reactions downstream, leading to cerebral aneurysm development. Because no significant differences were observed in the anatomy of the circle of Willis between the $P 2 X 4^{+/+}$ and $P 2 X 4^{-/-}$mice (Fig. 2), it seems that the aneurysm induction was not suppressed by anatomical differences.

A cerebral aneurysm may be recognized as a chronic

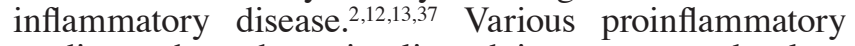
mediators have been implicated in aneurysm development, growth, and rupture. ${ }^{2,12,13,37}$ In the present study, the expressions of COX-2, MCP-1, TNF $\alpha$, iNOS, and IL-1 $\beta$ were significantly increased in the rats after aneurysm generation (Figs. 3-5). The formation of cerebral aneurysms has been reported to be suppressed by the inhibition and/or disruption of these proinflammatory mediators, and MCP-1 and COX-2 are induced in human, rat, and mouse

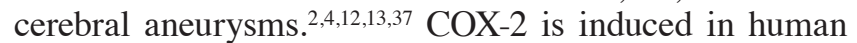
cultured endothelial cells in response to high WSS application. ${ }^{3}$ During the early phase of cerebral aneurysm development under enhanced WSS-related hemodynamics, a positive signaling pathway consisting of $\mathrm{COX}-2$, prostaglandin E2, and prostaglandin E receptor 2 may be formed by the induction of MCP-1 and subsequent recruitment of macrophages. ${ }^{2,13}$

In the present study, the immunoreactivities of COX-2 and iNOS in the whole arterial wall were lower in $P 2 X^{-/-}$ mice than control mice after aneurysm-inducing surgery
(Figs. 6 and 7). Interestingly, however, MCP-1 immunolabeling was reduced in the endothelium, but not in the adventitia, of the $P 2 X^{-/-}$mice postsurgery (Fig. 8). The disruption of $\mathrm{P} 2 \mathrm{X} 4$ did not completely inhibit the induction of cerebral aneurysms (Table 2). Additional mechanism(s) associated with the MCP-1 induction in the adventitia (e.g., stretching ${ }^{27}$ ) may be involved in the aneurysm development.

Vascular endothelial cells can respond to WSS in a physiological range to regulate blood flow by adjusting their shape, cytoplasmic properties, gene expression, and release of biochemical mediators. ${ }^{41}$ Several studies support our hypothesis that increased WSS above physiological levels is involved in cerebral aneurysm development. ${ }^{1,28,32}$ High WSS is associated with de novo human cerebral aneurysm development. ${ }^{28}$ The results of a study using experimentally induced BA aneurysms in rabbits suggested that the aneurysm induction is related to some threshold of the normal physiological limits of WSS. ${ }^{32}$

Although inflammation was conventionally thought to be promoted in blood vessels under low-WSS conditions, it was recently revealed that high WSS also induces inflammation. ${ }^{11}$ Not only the magnitude but also the disturbance of WSS is involved in inflammation. ${ }^{36}$ Disturbed WSS causes sustained molecular signaling in proinflammatory pathways, whereas steady WSS causes only a transient activation of these pathways. ${ }^{9}$ Inflammatory signaling is highly sensitive to pulse-wave frequencies and the magnitude and direction of flow. ${ }^{7}$ We are currently examining what types of hemodynamic environments are involved in cerebral aneurysm growth and rupture by using computational fluid dynamic techniques. ${ }^{17}$

The mechanisms by which enhanced WSS-related hemodynamics lead to the expression of inflammatory contributors to aneurysm formation remain unknown. However, similar mechanisms in association with P2X4 have been reported in other cells. P2X 4 is also expressed in podocytes in the kidneys. ${ }^{10}$ Glomerular hypertension causes podocyte damage, progressing to glomerulosclerosis; interestingly, the stretching of podocytes during this process has been suggested to activate $\mathrm{P} 2 \mathrm{X} 4$, leading to an upregulation of COX-2. ${ }^{10} \mathrm{P} 2 \mathrm{X} 7$, which belongs to the $\mathrm{P} 2 \mathrm{X}$ family (as does P2X4), is known to be an important cellsurface regulator of IL-1 $\beta$ and $\mathrm{TNF} \alpha{ }^{29} \mathrm{P} 2 \mathrm{X} 7$ promotes endothelial inflammation at low WSS with disturbed flow by transducing adenosine 5 '-triphosphate signals into p38 activation. ${ }^{18}$ At high WSS with disturbed flow, a P2X4related WSS response of endothelial cells may involve an inflammatory process followed by cerebral aneurysm formation.

$\mathrm{P} 2 \mathrm{X} 4$ receptors are generally less sensitive to the broad $\mathrm{P} 2 \mathrm{X}$ antagonists, such as suramin. ${ }^{39}$ Paroxetine is one of the most powerful selective inhibitiors for rat and human $\mathrm{P} 2 \mathrm{X} 4$ receptors, with median inhibitory concentration $\left(\mathrm{IC}_{50}\right)$ values of $2.45 \mu \mathrm{M}$ and $1.87 \mu \mathrm{M}$, respectively. ${ }^{34}$ Paroxetine can be used both in vivo and in vitro. Zarei et al. used paroxetine (10 $\mathrm{mg} / \mathrm{kg} / \mathrm{day}$, intraperitoneally) as a P2X4 inhibitor for rats. ${ }^{43}$ In addition to paroxetine, 5-BDBD and PSB-12062 have been reported to act as selective antagonists of human and rat $\mathrm{P} 2 \mathrm{X} 4$ in vitro, but not in vivo. ${ }^{39}$ Paroxetine has been used clinically as an anti- 

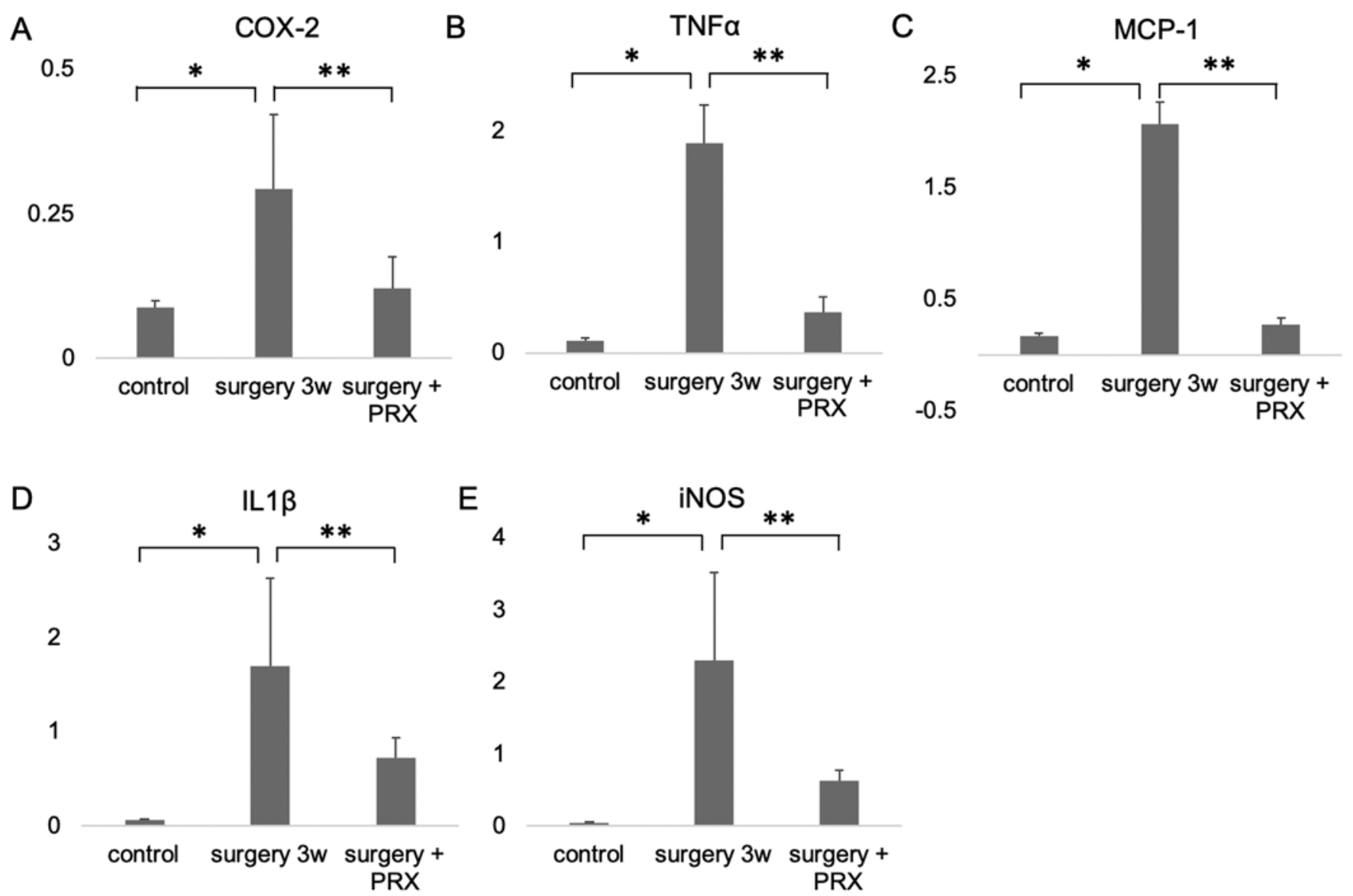

FIG. 5. Bar graphs showing the protein expressions of COX-2 (A), TNF $\alpha$ (B), MCP-1 (C), IL-1 (D), and iNOS (E) in experimentally induced cerebral aneurysms in female rats by Western blotting analysis. The protein expression was normalized to GAPDH expression, and the relative values (mean $\pm \mathrm{SD}$ ) are shown. Correlations were examined by an ANOVA followed by the Tukey-Kramer honestly significant difference test. Control: rats without surgery $(n=5)$; surgery $3 w$ : rats euthanized 3 weeks after aneurysminducing surgery $(n=6)$; surgery+PRX: rats euthanized 3 weeks after aneurysm-inducing surgery and paroxetine treatment for 3 weeks $(n=6)$. ${ }^{*}$ Control versus surgery $3 w, p=0.0035(A), p<0.0001(B), p<0.0001(C), p=0.0005(D)$, and $p=0.0010(E)$. ${ }^{* *}$ Surgery $3 w$ versus surgery+PRX, $p=0.0088(A), p<0.0001(B), p<0.0001(C), p=0.0043(D)$, and $p=0.0277(E)$.

depressant by a different mechanism of action from P2X4 inhibition, and it was confirmed to present no major safety issues for humans. ${ }^{6,25}$ The dose of paroxetine as an antidepressant for humans is $20-60 \mathrm{mg}$ daily. ${ }^{6}$ In the present experiment, rats were given paroxetine at $0.8 \mathrm{mg} / \mathrm{kg} / \mathrm{day}$. Considering that the $\mathrm{IC}_{50}$ is slightly smaller in humans than in rats, these doses were considered to be comparable. ${ }^{34}$

In the present study, not only formation but also growth of rat cerebral aneurysms was significantly diminished due to P2X4 inhibition. The application of paroxetine for the final week led to a significant reduction of the aneurysm size in rats euthanized 3 weeks after aneurysm-inducing surgery (Table 3 ). Additionally, the aneurysm size in rats euthanized 3 weeks after aneurysm-inducing surgery that received paroxetine treatment from 2 weeks after the surgery tended to be smaller than that in rats euthanized 2 weeks after the surgery. An aneurysm was already formed in all rats euthanized 2 weeks after aneurysm-inducing surgery. Although it is not clear whether the inhibitor can directly suppress aneurysm rupture, aneurysm growth is one of the highest risks for rupture. ${ }^{12}$ Therefore, paroxetine may be able to diminish rupture by suppressing aneurysm growth. Reduced enlargement of unruptured aneurysms may be clinically significant. This P2X4 inhibitor could thus be a potential clinical therapeutic agent against cerebral aneurysm. In addition, patients who are informed of the existence of an unruptured cerebral aneurysm at a clinical site are often depressed. Therefore, administration of paroxetine in an antidepressant capacity might also be useful for these patients. Similar hemodynamic involvement is also assumed for recanalization after coil embolization of a cerebral aneurysm,,$^{30}$ and paroxetine administration may also be effective in preventing a recurrence of the aneurysm.

Few agents with the potential to act against chronic inflammation during cerebral aneurysm development have been reported. . $^{3,19,31,38}$ Statins suppress the progression of experimentally induced cerebral aneurysms in rats by inhibiting the nuclear factor $\kappa \mathrm{B}$ pathway. ${ }^{2}$ In clinical studies the use of lipid-lowering agents (including statins) was inversely associated with ruptured cerebral aneurysms. ${ }^{8}$ Aspirin may be applicable for clinical use in this context, because aspirin prevents aneurysmal subarachnoid hemorrhage by reducing COX-2 and microsomal prostaglandin 


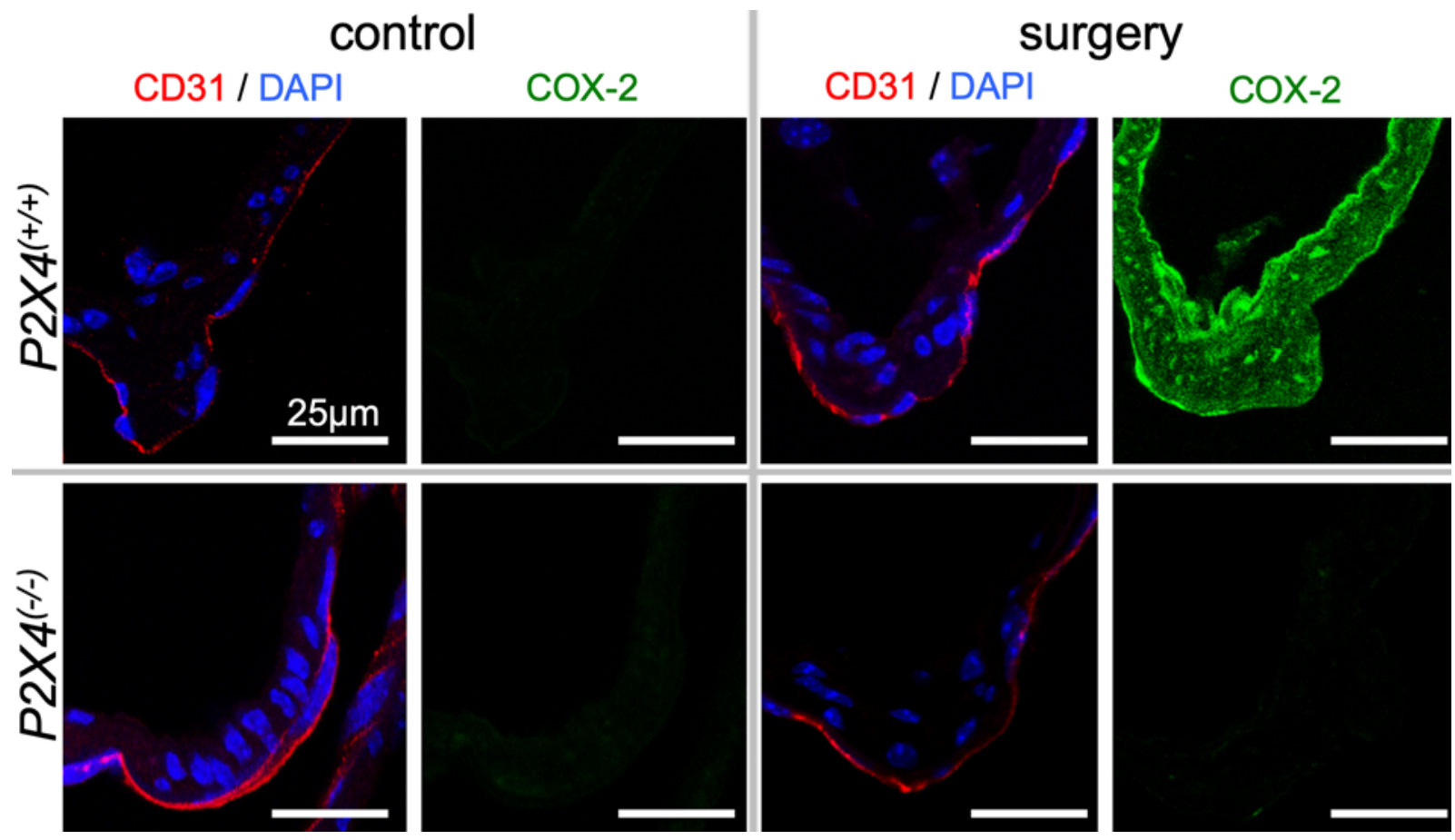

FIG. 6. Representative images of immunolabels for COX-2 in control $P 2 X 4^{+/+}$mice (upper left panels), $P 2 X 4^{+/+}$mice with aneurysm-inducing surgery (upper right panels), control $P 2 X 4^{-1-}$ mice (lower left panels), and $P 2 X 4^{-1-}$ mice with aneurysm-inducing surgery (lower right panels). Green indicates the immunolabel of the induced mediator, and red and blue indicate immunolabels for CD31 and DAPI, respectively.

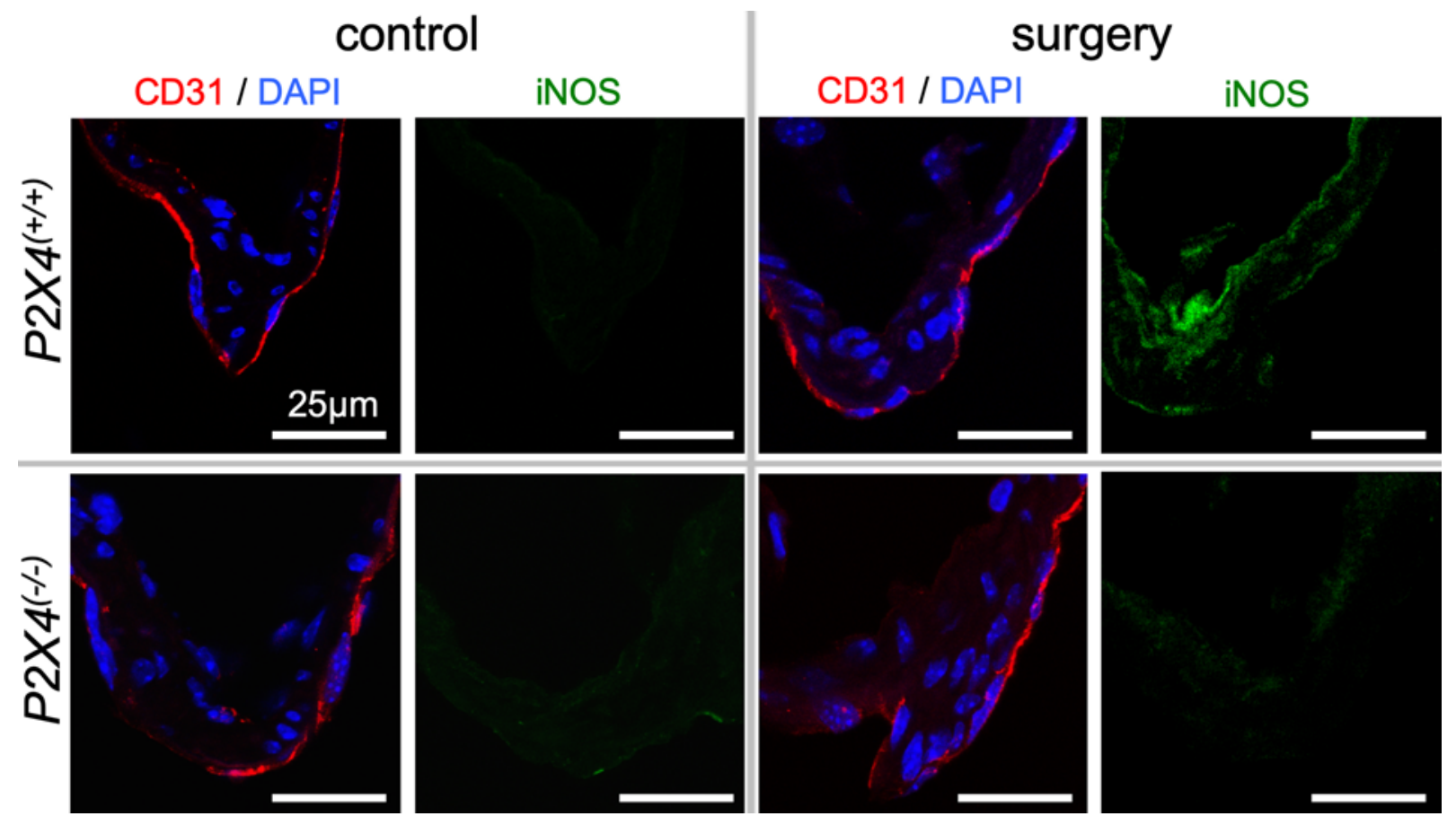

FIG. 7. Representative images of immunolabels for iNOS in control $P 2 X 4^{+/+}$mice (upper left panels), $P 2 X 4^{+/+}$mice with aneurysminducing surgery (upper right panels), control $P 2 X 4^{-1-}$ mice (lower left pane/s), and $P 2 X 4^{-1-}$ mice with aneurysm-inducing surgery (lower right pane/s). Green indicates the immunolabel of the induced mediator, and red and blue indicate immunolabels for CD31 and DAPI, respectively. 


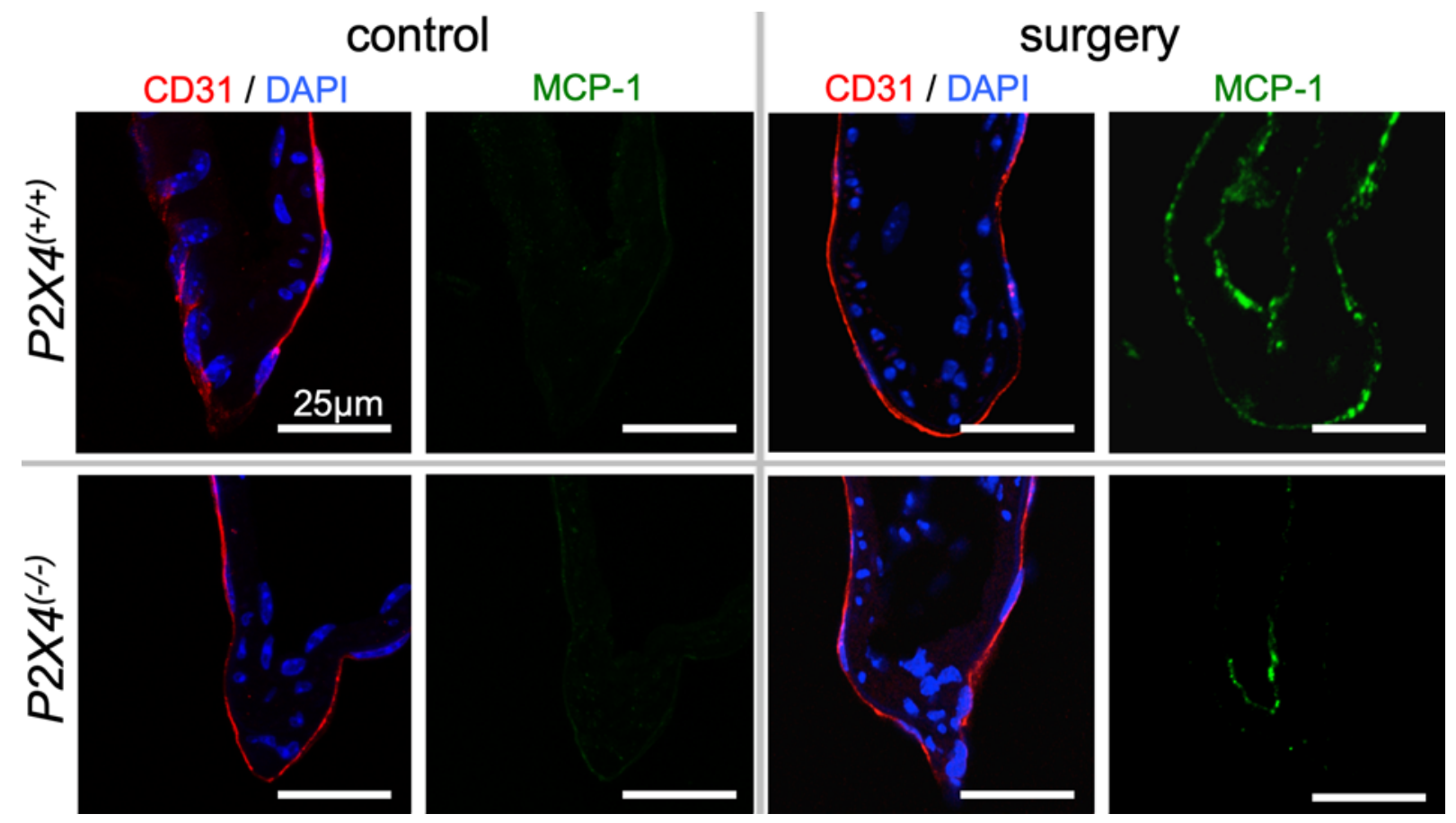

FIG. 8. Representative images of immunolabels for MCP-1 in control $P 2 X 4^{+/+}$mice (upper left panels), $P 2 X 4^{+/+}$mice with aneurysm-inducing surgery (upper right panels), control $P 2 X 4^{-1-}$ mice (lower left panels), and $P 2 X 4^{-- \text {- }}$ mice with aneurysm-inducing surgery (lower right panels). Green indicates the immunolabel of the induced mediator, and red and blue indicate immunolabels for CD31 and DAPI, respectively. Note that the MCP-1 immunolabeling density in the endothelium (the CD31-positive cell layer), but not that in the adventitia, is lower in $P 2 X 4^{-/-}$mice than in $P 2 X 4^{+/+}$mice after aneurysm-inducing surgery.

E2 synthase $1 .{ }^{19}$ Although it is possible that aspirin would increase the amount of bleeding once the aneurysm ruptures, at least one study has reported that aspirin did not, in fact, increase the rate of bleeding complications following aneurysm rupture. ${ }^{38}$ Among individuals with an unruptured cerebral aneurysm, the proportion of elderly people is high. Aspirin treatment for patients with peptic ulcers or the bleeding tendencies sometimes seen in the elderly should thus be carefully monitored. ${ }^{23}$ Tetracycline is also reported to be effective in preventing aneurysmal rupture in mice. ${ }^{31}$

The present study has some limitations. In addition to vascular endothelial cells, $\mathrm{P} 2 \mathrm{X} 4$ is expressed in various organs and plays several different roles in the human body. ${ }^{5}$ It is thus possible that P2X4 suppressed cerebral aneurysm formation by one or more of its other functions.

\section{Conclusions}

Enhanced shear stress-associated hemodynamic stress on the vascular endothelium may cause the inflammatory process in cerebral aneurysm formation. Here we observed that both the disruption and the inhibition of P2X4 purinoceptor, which is involved in flow-sensitive mechanisms that regulate vascular remodeling, resulted in a significant reduction of experimentally induced cerebral aneurysm formation and enlargement in animals. Treatment with the P2X4 inhibitor paroxetine significantly suppressed the expression levels of inflammatory mediators that contribute to cerebral aneurysm development, i.e., COX-2, MCP-1, TNF $\alpha$, iNOS, and IL-1 $\beta$. Paroxetine may be a potential clinical remedy for cerebral aneurysms, given that it may weaken aneurysm growth and that it has been used safely in humans as an antidepressant.

\section{Acknowledgments}

This work was supported by the Japan Agency for Medical Research and Development (AMED) under grant no. JP15gm0810006h0301, by a JSPS KAKENHI grant (no. 15K10323), and by The Shimizu Foundation for Immunology and Neuroscience. We thank Dr. Geert W. Schmid-Schönbein, Chair of the Department of Bioengineering, University of California, San Diego, for his valuable advice, and Dr. Tomohiro Aoki, Department of Molecular Pharmacology, National Cerebral and Cardiovascular Center, for his generous gift of the special chow for mice and the use of the confocal fluorescence microscope.

\section{References}

1. Alfano JM, Kolega J, Natarajan SK, Xiang J, Paluch RA, Levy EI, et al: Intracranial aneurysms occur more frequently at bifurcation sites that typically experience higher hemodynamic stresses. Neurosurgery 73:497-505, 2013

2. Aoki T, Fròsen J, Fukuda M, Bando K, Shioi G, Tsuji K, et al: Prostaglandin $\mathrm{E}_{2}-\mathrm{EP} 2-\mathrm{NF}-\mathrm{\kappa B}$ signaling in macrophages as a potential therapeutic target for intracranial aneurysms. Sci Signal 10:eaah6037, 2017

3. Aoki T, Kataoka H, Ishibashi R, Nozaki K, Hashimoto N: Simvastatin suppresses the progression of experimentally induced cerebral aneurysms in rats. Stroke 39:1276-1285, 2008

4. Aoki T, Nishimura M, Matsuoka T, Yamamoto K, Furuyashiki T, Kataoka $\mathrm{H}$, et al: $\mathrm{PGE}_{2} \mathrm{EP}_{2}$ signalling in endothelium is activated by haemodynamic stress and induces cerebral aneu- 
rysm through an amplifying loop via NF- $\kappa \mathrm{B}$. Br J Pharmacol 163:1237-1249, 2011

5. Bo X, Kim M, Nori SL, Schoepfer R, Burnstock G, North RA: Tissue distribution of $\mathrm{P} 2 \mathrm{X} 4$ receptors studied with an ectodomain antibody. Cell Tissue Res 313:159-165, 2003

6. Børup C, Meidahl B, Petersen IM, Vangtorp A, le Fèvre Honoré P: An early clinical phase II evaluation of paroxetine, a new potent and selective 5HT-uptake inhibitor in patients with depressive illness. Pharmacopsychiatria 15:183-186, 1982

7. Bryan MT, Duckles H, Feng S, Hsiao ST, Kim HR, Serbanovic-Canic J, et al: Mechanoresponsive networks controlling vascular inflammation. Arterioscler Thromb Vasc Biol 34:2199-2205, 2014

8. Can A, Castro VM, Dligach D, Finan S, Yu S, Gainer V, et al: Lipid-lowering agents and high HDL (high-density lipoprotein) are inversely associated with intracranial aneurysm rupture. Stroke 49:1148-1154, 2018

9. Chien S: Effects of disturbed flow on endothelial cells. Ann Biomed Eng 36:554-562, 2008

10. Endlich K, Kliewe F, Endlich N: Stressed podocytes-mechanical forces, sensors, signaling and response. Pflugers Arch 469:937-949, 2017

11. Eshtehardi P, Brown AJ, Bhargava A, Costopoulos C, Hung OY, Corban MT, et al: High wall shear stress and high-risk plaque: an emerging concept. Int J Cardiovasc Imaging 33:1089-1099, 2017

12. Etminan N, Rinkel GJ: Unruptured intracranial aneurysms: development, rupture and preventive management. Nat Rev Neurol 12:699-713, 2016

13. Fukuda M, Aoki T: Molecular basis for intracranial aneurysm formation. Acta Neurochir Suppl 120:13-15, 2015

14. Fukuda M, Aoki T, Manabe T, Maekawa A, Shirakawa T, Kataoka H, et al: Exacerbation of intracranial aneurysm and aortic dissection in hypertensive rat treated with the prostaglandin F-receptor antagonist AS604872. J Pharmacol Sci 126:230-242, 2014

15. Fukuda S, Hashimoto N, Naritomi H, Nagata I, Nozaki K, Kondo S, et al: Prevention of rat cerebral aneurysm formation by inhibition of nitric oxide synthase. Circulation 101:25322538, 2000

16. Fukuda S, Hashimoto N, Nozaki K, Nishimura M: Pathogenesis of cerebral aneurysms: evidences using experimentally induced cerebral aneurysm models. Asian Biomed 3:229236, 2009

17. Fukuda S, Shimogonya Y, Yonemoto N: Differences in cerebral aneurysm rupture rate according to arterial anatomies depend on the hemodynamic environment. AJNR Am J Neuroradiol 40:834-839, 2019

18. Green JP, Souilhol C, Xanthis I, Martinez-Campesino L, Bowden NP, Evans PC, et al: Atheroprone flow activates inflammation via endothelial ATP-dependent P2X7-p38 signalling. Cardiovasc Res 114:324-335, 2018

19. Hasan DM, Mahaney KB, Brown RD Jr, Meissner I, Piepgras DG, Huston J, et al: Aspirin as a promising agent for decreasing incidence of cerebral aneurysm rupture. Stroke 42:3156-3162, 2011

20. Hashimoto N, Handa H, Hazama F: Experimentally induced cerebral aneurysms in rats. Surg Neurol 10:3-8, 1978

21. Hashimoto N, Kim C, Kikuchi H, Kojima M, Kang Y, Hazama F: Experimental induction of cerebral aneurysms in monkeys. J Neurosurg 67:903-905, 1987

22. Hazama F, Kataoka H, Yamada E, Kayembe K, Hashimoto N, Kojima M, et al: Early changes of experimentally induced cerebral aneurysms in rats. Light-microscopic study. Am J Pathol 124:399-404, 1986

23. Higuchi T, Iwakiri R, Hara M, Shimoda R, Sakata Y, Nakayama A, et al: Low-dose aspirin and comorbidities are significantly related to bleeding peptic ulcers in elderly patients compared with nonelderly patients in Japan. Intern Med 53:367-373, 2014

24. Kaspera W, Ładziński P, Larysz P, Hebda A, Ptaszkiewicz K, Kopera M, et al: Morphological, hemodynamic, and clinical independent risk factors for anterior communicating artery aneurysms. Stroke 45:2906-2911, 2014

25. Kaye CM, Haddock RE, Langley PF, Mellows G, Tasker TC, Zussman BD, et al: A review of the metabolism and pharmacokinetics of paroxetine in man. Acta Psychiatr Scand Suppl 350:60-75, 1989

26. Kayembe KNT, Sasahara M, Hazama F: Cerebral aneurysms and variations in the circle of Willis. Stroke 15:846-850, 1984

27. Koseki H, Miyata H, Shimo S, Ohno N, Mifune K, Shimano $\mathrm{K}$, et al: Two diverse hemodynamic forces, a mechanical stretch and a high wall shear stress, determine intracranial aneurysm formation. Transl Stroke Res [epub ahead of print], 2019

28. Kulcsár Z, Ugron A, Marosfoi M, Berentei Z, Paál G, Szikora I: Hemodynamics of cerebral aneurysm initiation: the role of wall shear stress and spatial wall shear stress gradient. AJNR Am J Neuroradiol 32:587-594, 2011

29. Lister MF, Sharkey J, Sawatzky DA, Hodgkiss JP, Davidson DJ, Rossi AG, et al: The role of the purinergic P2X7 receptor in inflammation. J Inflamm (Lond) 4:5, 2007

30. Luo B, Yang X, Wang S, Li H, Chen J, Yu H, et al: High shear stress and flow velocity in partially occluded aneurysms prone to recanalization. Stroke 42:745-753, 2011

31. Makino H, Tada Y, Wada K, Liang EI, Chang M, Mobashery S, et al: Pharmacological stabilization of intracranial aneurysms in mice: a feasibility study. Stroke 43:2450-2456, 2012

32. Metaxa E, Tremmel M, Natarajan SK, Xiang J, Paluch RA, Mandelbaum M, et al: Characterization of critical hemodynamics contributing to aneurysmal remodeling at the basilar terminus in a rabbit model. Stroke 41:1774-1782, 2010

33. Morimoto M, Miyamoto S, Mizoguchi A, Kume N, Kita T, Hashimoto N: Mouse model of cerebral aneurysm: experimental induction by renal hypertension and local hemodynamic changes. Stroke 33:1911-1915, 2002

34. Nagata K, Imai T, Yamashita T, Tsuda M, Tozaki-Saitoh H, Inoue K: Antidepressants inhibit $\mathrm{P} 2 \mathrm{X} 4$ receptor function: a possible involvement in neuropathic pain relief. Mol Pain 5:20, 2009

35. Nakatani H, Hashimoto N, Kang Y, Yamazoe N, Kikuchi $\mathrm{H}$, Yamaguchi S, et al: Cerebral blood flow patterns at major vessel bifurcations and aneurysms in rats. J Neurosurg 74:258-262, 1991

36. Shimogonya Y, Fukuda S: Computational and experimental studies into the hemodynamics of cerebral aneurysms. J Biomech Sci Eng 11:15-00488, 2016

37. Signorelli F, Sela S, Gesualdo L, Chevrel S, Tollet F, PaillerMattei C, et al: Hemodynamic stress, inflammation, and intracranial aneurysm development and rupture: a systemic review. World Neurosurg 115:234-244, 2018

38. Starke RM, Chalouhi N, Ding D, Hasan DM: Potential role of aspirin in the prevention of aneurysmal subarachnoid hemorrhage. Cerebrovasc Dis 39:332-342, 2015

39. Stokes L, Layhadi JA, Bibic L, Dhuna K, Fountain SJ: P2X4 receptor function in the nervous system and current breakthroughs in pharmacology. Front Pharmacol 8:291, 2017

40. Waga S, Okada M, Kojima T: Saccular aneurysm associated with absence of the left cervical carotid arteries. Neurosurgery 3:208-212, 1978

41. Yamamoto K, Ando J: New molecular mechanisms for cardiovascular disease: blood flow sensing mechanism in vascular endothelial cells. J Pharmacol Sci 116:323-331, 2011

42. Yamamoto K, Sokabe T, Matsumoto T, Yoshimura K, Shibata $\mathrm{M}$, Ohura N, et al: Impaired flow-dependent control of vas- 
cular tone and remodeling in P2X4-deficient mice. Nat Med 12:133-137, 2006

43. Zarei M, Sabetkasaei M, Moini Zanjani T: Paroxetine attenuates the development and existing pain in a rat model of neurophatic pain. Iran Biomed J 18:94-100, 2014

\section{Disclosures}

The authors report no conflict of interest concerning the materials or methods used in this study or the findings specified in this paper.

\section{Author Contributions}

Conception and design: S Fukuda. Acquisition of data: S Fukuda, M Fukuda, Suzuki, Niwa, Inoue. Analysis and interpretation of data: S Fukuda, M Fukuda, Ando, Yamamoto. Drafting the article: S Fukuda, M Fukuda, Ando, Tsukahara. Critically revising the article: S Fukuda, M Fukuda, Ando, Yamamoto, Niwa, Inoue, Satoh-Asahara, Hasegawa, Shimatsu, Tsukahara. Reviewed submitted version of manuscript: S Fukuda, M Fukuda, Ando, Yamamoto, Suzuki, Inoue, Satoh-Asahara, Hasegawa, Shimatsu, Tsukahara. Approved the final version of the manuscript on behalf of all authors: S Fukuda. Statistical analysis: S Fukuda, Yonemoto. Administrative/technical/material support: Ando, Yamamoto, Suzuki, Niwa, Satoh-Asahara. Study supervision: S Fukuda, Shimatsu.

\section{Supplemental Information}

Previous Presentations

Portions of this work were presented in poster form at the International Stroke Conference 2018 in Los Angeles, CA, on January 24, 2018, and at Experimental Biology 2018 in San Diego, CA, on April 23, 2018.

\section{Correspondence}

Shunichi Fukuda: National Hospital Organization Kyoto Medical Center, Kyoto City, Kyoto, Japan. fukudashunichi@gmail.com. 